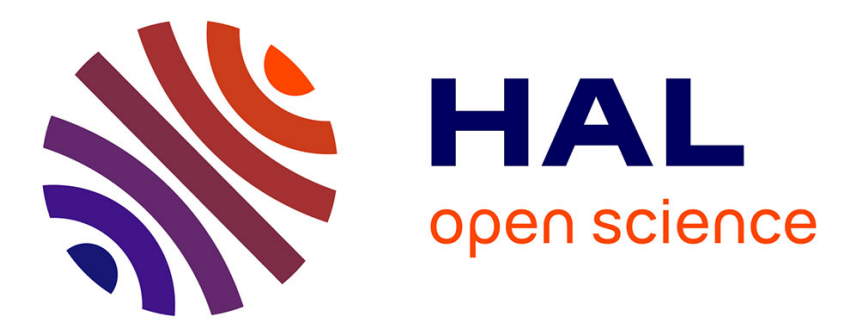

\title{
Modal behavior of a new large reflector conceptual design
}

Sébastien Morterolle, Bernard Maurin, Jean-François Dubé, Julien Averseng, Jérôme Quirant

\section{To cite this version:}

Sébastien Morterolle, Bernard Maurin, Jean-François Dubé, Julien Averseng, Jérôme Quirant. Modal behavior of a new large reflector conceptual design. Aerospace Science and Technology, 2015, 42, pp.74-79. 10.1016/j.ast.2015.01.002 . hal-01235730

\section{HAL Id: hal-01235730 \\ https://hal.science/hal-01235730}

Submitted on 21 Oct 2016

HAL is a multi-disciplinary open access archive for the deposit and dissemination of scientific research documents, whether they are published or not. The documents may come from teaching and research institutions in France or abroad, or from public or private research centers.
L'archive ouverte pluridisciplinaire HAL, est destinée au dépôt et à la diffusion de documents scientifiques de niveau recherche, publiés ou non, émanant des établissements d'enseignement et de recherche français ou étrangers, des laboratoires publics ou privés.

\section{(1) (1) $\$$}

Distributed under a Creative Commons Attribution - NonCommercial - NoDerivatives| 4.0 


\title{
Modal behavior of a new large reflector conceptual design
}

\author{
Sébastien Morterolle ${ }^{\mathrm{a}, *}$, Bernard Maurin ${ }^{\mathrm{b}}$, Jean-François Dube ${ }^{\mathrm{b}}$, Julien Averseng ${ }^{\mathrm{b}}$, \\ Jérôme Quirant ${ }^{\mathrm{b}}$ \\ a Université de Lyon, INSA-Lyon, LaMCoS, CNRS, UMR5259, F-69621, France \\ ${ }^{\mathrm{b}}$ Université Montpellier 2, LMGC, CNRS, UMR5508, CC48, Place E. Bataillon, 34095 Montpellier cedex 5, France
}

\begin{abstract}
A B S T R A C T
A new conceptual design for the architecture of a large deployable space reflector is presented. The reflective parabolic surface is made of a mesh shaped by a cable net and the supporting rim structure is based on scissor mechanisms associated with flexible joints. These joints replace complex articulations while allowing the storage of the energy required for deployment. They also affect the stiffness of the structure and the tension of the cable net. The dynamic behavior was studied by finite element modeling and through tests on an experimental prototype with a gravity compensation device. We focused on the first natural mode, which is an important design criterion for space applications. The measurements are compared to simulation results and we discuss the influence of suspension threads and gravity in the model.
\end{abstract}

Keywords:

Space antenna

Deployable reflector

Modal analysis

Tension truss

\section{Introduction}

Large parabolic reflectors are now being developed to meet the growing need for telecommunications facilities. Reflectors of greater than $10 \mathrm{~m}$ diameter are deployable because of their incompatibility with the volume available in the launch capsule.

The main large parabolic reflector concepts are presented in several previous reports [9,2]. Concepts based on a deployable rim structure with a parabolic surface made of a reflective mesh supported by a cable net seem to be the most promising because they are light, have no elements behind the reflecting surface and have good surface accuracy for high frequency transmissions. The AstroMesh antenna developed by TRW Astro Aerospace is clearly the most renowned of all existing large reflectors [8]. It is composed of two symmetrical composite cable nets attached to a truss rim structure (Fig. 1), which is made of composite tubes arranged in deformable parallelograms, and a reflective mesh stretched on the upper net. The reflector is deployed by shortening a cable that runs continuously through the telescopic diagonal tubes and deployment synchronization is achieved through special joints with internal gears [6]. Several satellites with AstroMesh antenna have been launched since 2000 , which are operational for S-band $(2-4 \mathrm{GHz})$ to Ka-band (26.5-40 GHz) communication frequencies [7]. The total mass of a $12 \mathrm{~m}$ diameter reflector is $57 \mathrm{~kg}$ and its first natural

\footnotetext{
* Corresponding author.

E-mail address: sebastien.morterolle@insa-lyon.fr (S. Morterolle).
}

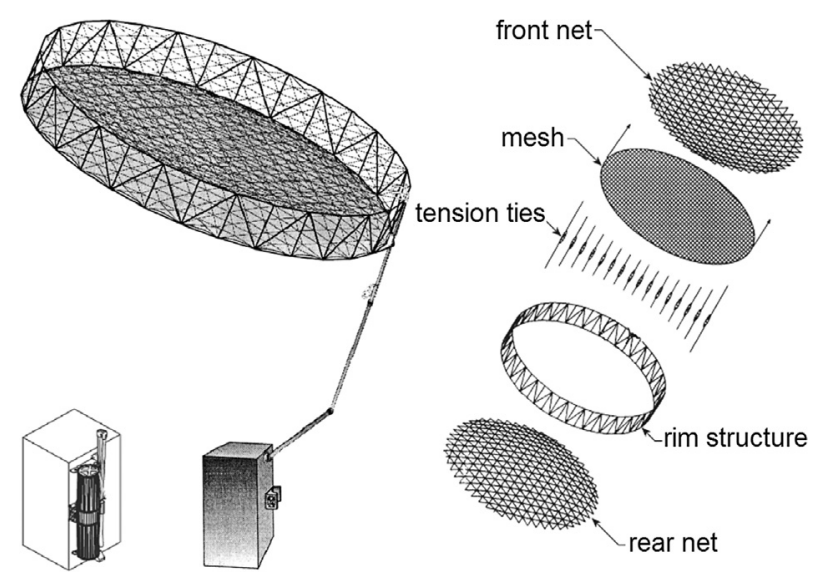

Fig. 1. The large deployable AstroMesh reflector.

frequency is $0.80 \mathrm{~Hz}$ [1]. In this configuration, the rim structure involves 30 parallelograms of $2.52 \mathrm{~m}$ height with a $1.26 \mathrm{~m}$ base.

A key design parameter for a large reflector is the frequency of its first natural mode. Indeed, being subjected to zero gravity in space, the deployed reflector should not be too sensitive to excitations from the Attitude and Orbit Control System (AOCS) that controls and steers the satellite in its orbit around the Earth. The frequency of the first mode of the reflector must therefore be outside the frequency range of the controlling signal, which is roughly between 0 and $1 \mathrm{~Hz}$. This key design specification guides choices 


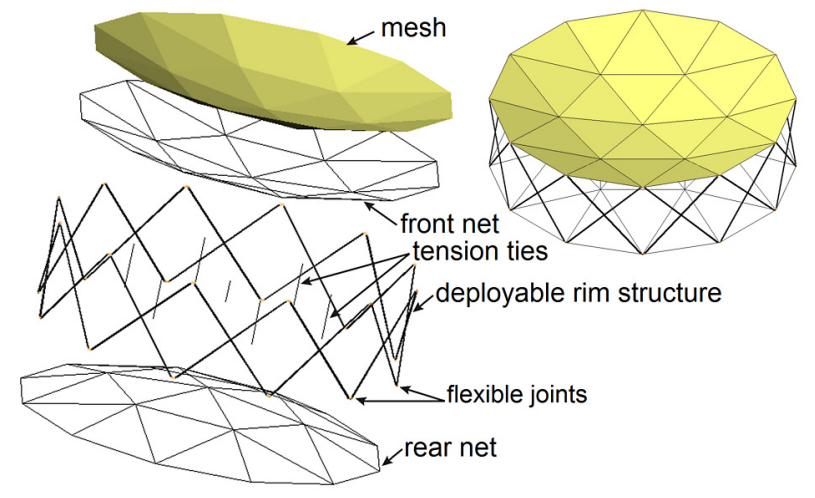

Fig. 2. Reflector concept.

in terms of architecture, stiffness and mass. Moreover, given current technologies, a mass per unit of deployed area of less than $500 \mathrm{~g} / \mathrm{m}^{2}$ is generally targeted. This represents a total mass of $56.5 \mathrm{~kg}$ for a $12 \mathrm{~m}$ diameter $\left(113 \mathrm{~m}^{2}\right)$ reflector.

In this paper, we address the modal analysis of a new conceptual large space reflector design and assess how to validate the simulations of its in-orbit behavior through ground testing. First, we introduce the reflector concept and particularly its innovative rim structure. We then present the numerical model that allows determining the first vibration modes and the impact of cable nets on the behavior. Next is presented a reduced scale prototype that was built to check the feasibility of the concept and to perform a series of tests. The measurements are compared with the simulations results if order to validate this numerical model for predicting the in-orbit behavior of the structure. As zero gravity conditions are difficult to reproduce on Earth for large lightweight structures, a method is proposed to account for the influence of a gravity compensation system in the model so as to justify the zero gravity simulations with ground test measurements.

\section{New space reflector concept}

Several concepts comparable to the AstroMesh system were studied, as that of Tibert and Pellegrino [10] based on a tensegrity structure, and that proposed by You and Pellegrino [12] with a cable-stiffened pantographic ring. However, these studies generally focused on the structural architecture or on the accuracy of the reflecting surface but not on the dynamic behavior. In this paper, we present a concept involving a scissor rim structure with flexible joints (Fig. 2).

Indeed, flexible joints can advantageously replace complex and heavier joints composed of several pivots oriented in accordance with the deployment kinematics. Each scissor opens in a plane corresponding to a side face of the rim structure, of polyhedral form, so the pivot axes at the center of bars should be perpendicular to this plane to be kinematically compliant. In addition, the joints between two consecutive scissors must be composed of two pivots with axes perpendicular to each side (Fig. 3a). Spherical joints may also be used, however they are seldom used in space applications (few certified models) and joints with only one degree of freedom are generally preferred. Also, spherical joints would increase the number of degrees of freedom, which is very detrimental to the deployment control. A three-pivot joint can be used to overcome this issue: one with its axis oriented perpendicular to the plane formed by the connected tubes and two along the axes of the tubes with rotation limited to few degrees (Fig. 3b).

Beside simplicity, flexible joints (Fig. 3c) bring the possibility to deploy the reflector by exploiting the accumulated deformation energy when folded. The rim structure may then be kept folded

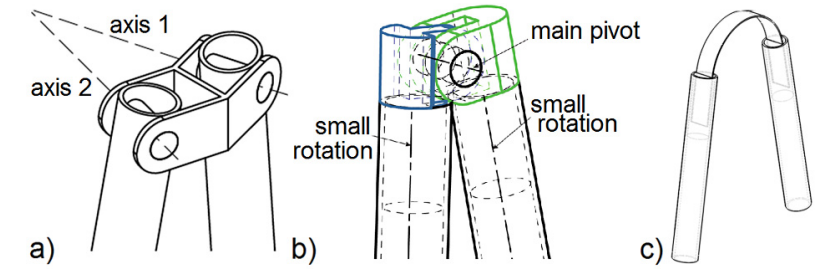

Fig. 3. a) Two-pivot joint; b) Three-pivot joint; c) Flexible joint.
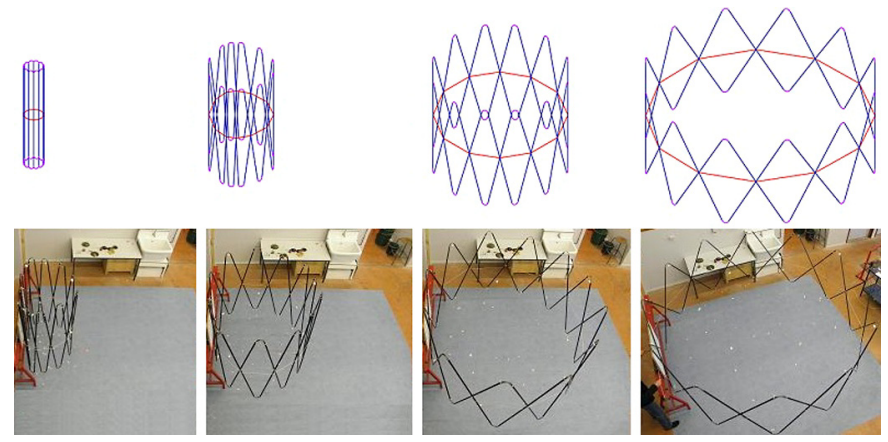

Fig. 4. Deployment of the scissor rim structure with flexible joints.

simply using ties, which would be released to initiate the reflector deployment.

The deployment of the scissor rim structure with flexible joints was numerically simulated using an implicit transient two-stage analysis (presented in Quirant et al. [5]). Deployment tests were also performed on a prototype (described in part 3 ) suspended by vertical threads on a rail system. A cord encircling the rim structure, slowly unrolled, was used to control the deployment. The tests and simulations demonstrated the feasibility of the concept; the deployment kinematics obtained are presented in Fig. 4.

\section{Modal characteristics in space}

To compare the modal behavior of a scissor rim structure with flexible joints to that of an operational reflector of the AstroMesh type, we simulated the behavior of a $12 \mathrm{~m}$ diameter model for the two architectures. In this study, the rim structure is composed of 30 sides (scissors or parallelograms) and the parabolic surface is supported by the same cable net for the two antennas. The parabolic surface characteristics (focal length $5.4 \mathrm{~m}$, center offset $8.3 \mathrm{~m}$ ) result in a front cable net depth of $67 \mathrm{~cm}$. The rim structures are also designed to have an identical mass.

\subsection{AstroMesh reference model}

The parameters of the "AstroMesh model" were determined by running a series of analyses to obtain a first frequency of $0.8 \mathrm{~Hz}$. For confidentiality reasons, it is very difficult to find the exact dimensions in the literature. In the numerical model (Fig. 5), we thus considered horizontal and vertical tubes with $62 \mathrm{~mm}$ diameter and $1 \mathrm{~mm}$ thickness. The diameter of the diagonal tubes is equal to one third of the others $(21 \mathrm{~mm})$. Tubes are made of carbon/epoxy composite $\left(1550 \mathrm{~kg} / \mathrm{m}^{3}\right.$, elastic modulus $\left.125 \mathrm{GPa}\right)$. The cable nets (including the reflective mesh mass) are modeled by cables with a $1 \mathrm{~mm}^{2}$ section, a $2500 \mathrm{~kg} / \mathrm{m}^{3}$ mass density and a $125 \mathrm{GPa}$ elastic modulus. These choices result in a total mass of $57.1 \mathrm{~kg}$, close to that of a $12 \mathrm{~m}$ AstroMesh (53 kg for the rim structure and $4.1 \mathrm{~kg}$ for the cable nets).

This reference model was investigated using the ANSYS ${ }^{\mathrm{TM}}$ finite elements software package. Each tube is composed of four Beam elements and each cable is represented by one Link element. The 

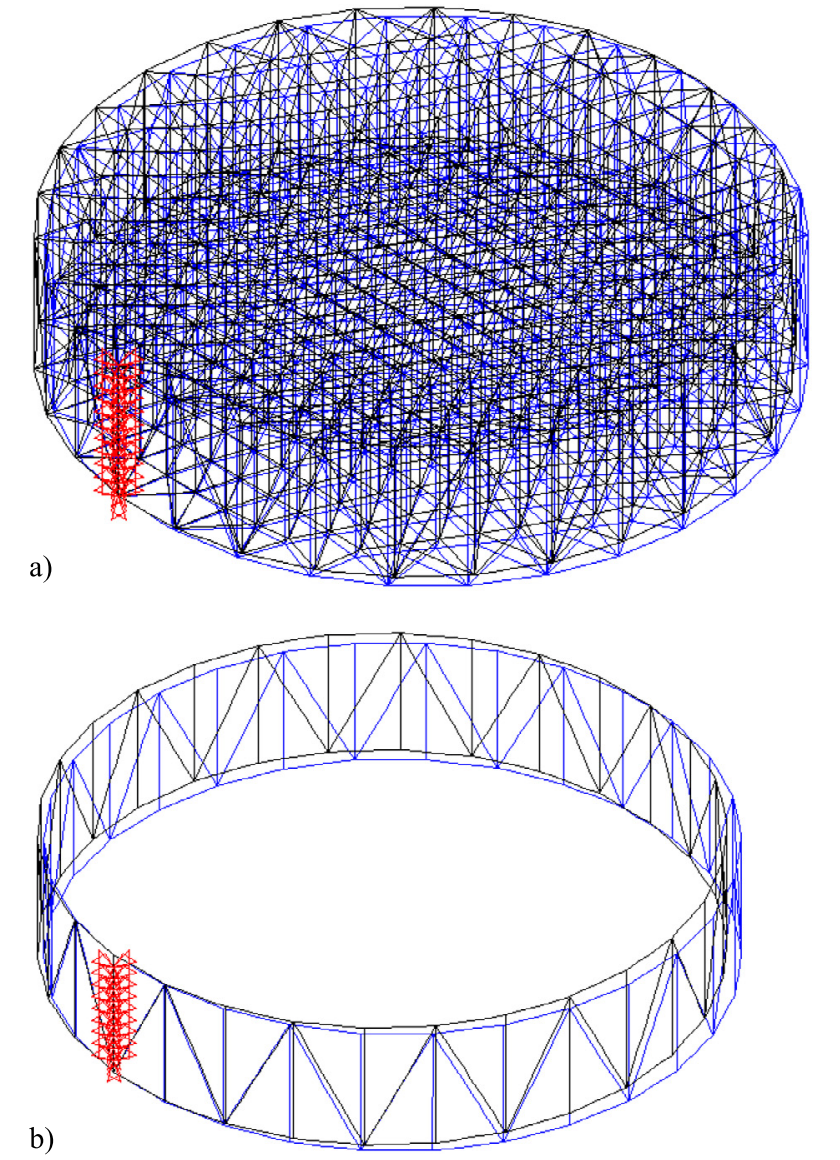

Fig. 5. First mode of (a) the AstroMesh model at $0.81 \mathrm{~Hz}$ and (b) its rim structure alone at $0.30 \mathrm{~Hz}$.

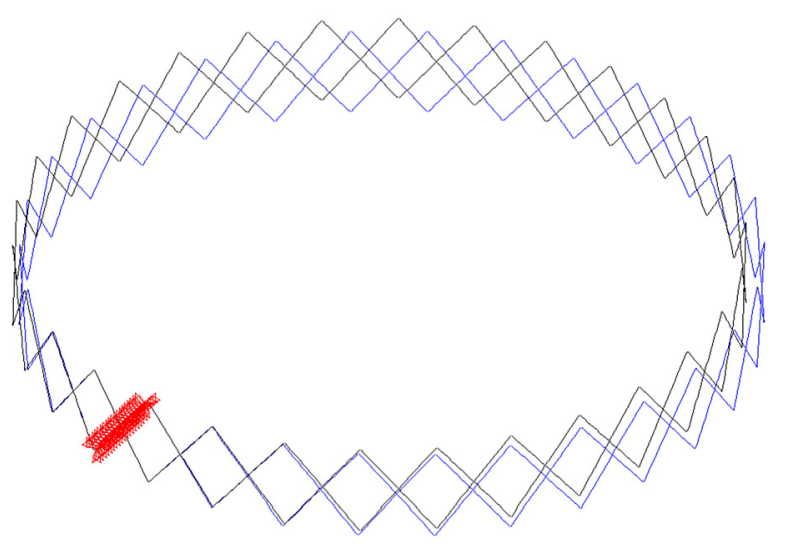

Fig. 6. First mode of the scissor frame at $0.36 \mathrm{~Hz}$.

reflector is also considered to be locked in its deployed configuration: the tubes are fixed together at their ends (coincident nodes are merged). One vertical tube of the rim structure is blocked to mimic the attachment to the arm of the satellite. The subspace method, suitable for large and detailed systems [11], was used to determine the first eigenfrequencies and their corresponding modes.

In this model, the first natural mode occurs at $0.81 \mathrm{~Hz}$ frequency. It corresponds to a global oscillation in the horizontal plane around the fixed tube axis (Fig. 5a). The shapes of the first vibration modes are similar to those presented by TRW Astro Aerospace for the $6 \mathrm{~m}$ diameter AstroMesh on the Osiris Antenna [4]. Moreover, the rim structure alone has a first natural frequency of $0.30 \mathrm{~Hz}$, with a same mode shape (Fig. 5b). This sharp
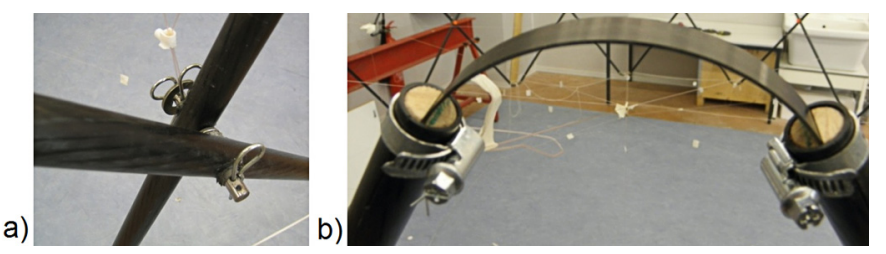

Fig. 7. (a) pivot and (b) flexible joint.

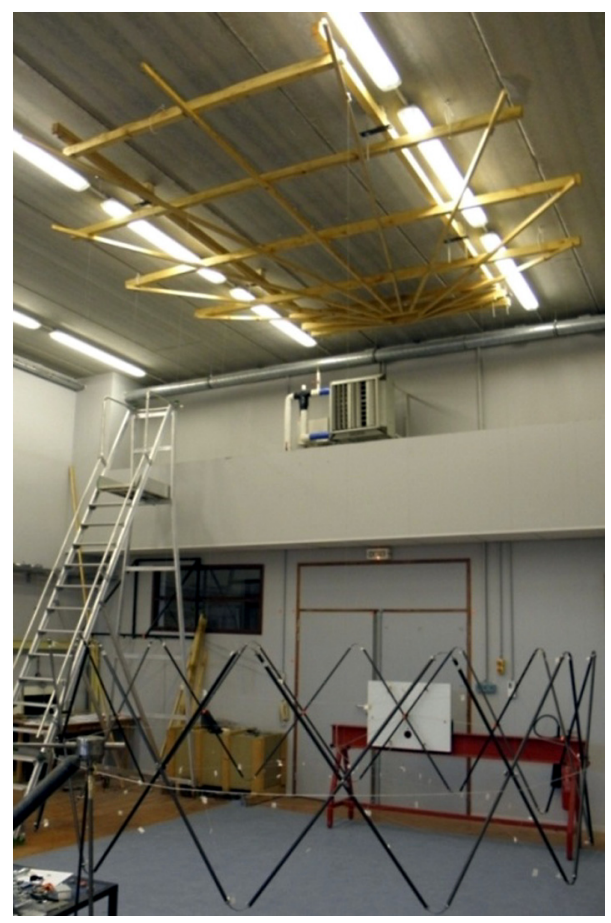

Fig. 8. The deployed prototype suspended and attached to a fixed frame.

difference in frequency shows that the cable nets greatly affect the antenna rigidity.

\subsection{Scissor frame models}

The height of the scissor frame is set at $1.6 \mathrm{~m}$ so as to be sufficiently high to generate the two symmetrical nets connected by vertical tension ties [3]. First, the structure is modeled as a single body with the same cross-sectional area everywhere (Fig. 6). The tubes are $75 \mathrm{~mm}$ diameter, $1.2 \mathrm{~mm}$ thickness, so the rim structure mass is $52.7 \mathrm{~kg}$ to match that of the AstroMesh reference structure. As seen previously, one tube is blocked to mimic the fixation to the satellite.

The resulting first natural frequency of this structure is $0.36 \mathrm{~Hz}$. The shape of the corresponding mode is similar to that of the reference model: the structure oscillates around the fixed tube (Fig. 6). By adding the two cable nets in the model, the frequency of this first mode rises to $0.87 \mathrm{~Hz}$, and the total mass reach $56.8 \mathrm{~kg}$ in that case (57.1 kg for the AstroMesh).

In order to evaluate the influence of the flexible joints in the first vibration mode, we modelled them accurately as carbon blades (same material as tubes) of length $120 \mathrm{~mm}$ with a rectangular section $(73 \mathrm{~mm} \times 1 \mathrm{~mm})$. The prestress in the structure is not considered here because it slightly affects the first mode frequency and requires a long computation time for the net tensioning. Flexible joints are thus modeled by BEAM elements with a rectangular section in their curved geometry. In this case, the first vibration mode occurs at $0.28 \mathrm{~Hz}$ for the frame alone $(50.2 \mathrm{~kg}$ ) and $0.72 \mathrm{~Hz}$ with the cable nets. With this precise modeling of the 


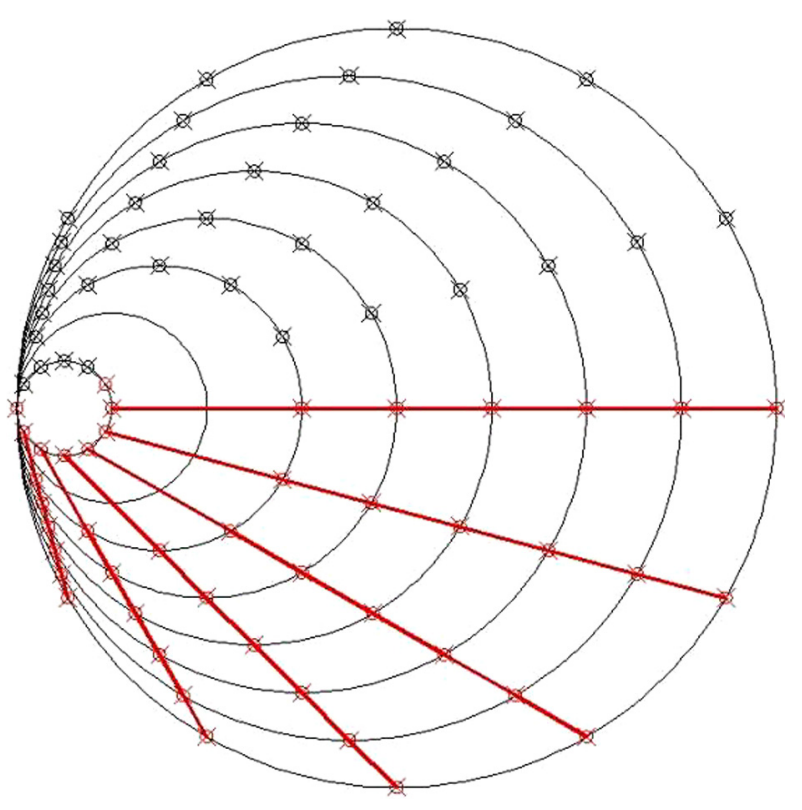

Fig. 9. Position of rails following the theoretical linear trajectories of the pivots.

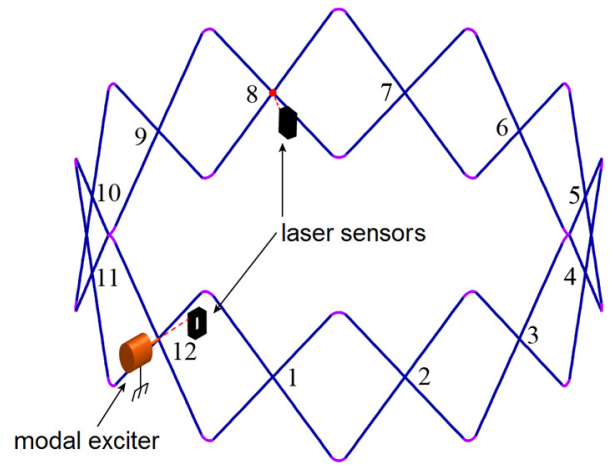

Fig. 10. Low frequency displacement response measurement using laser sensors.

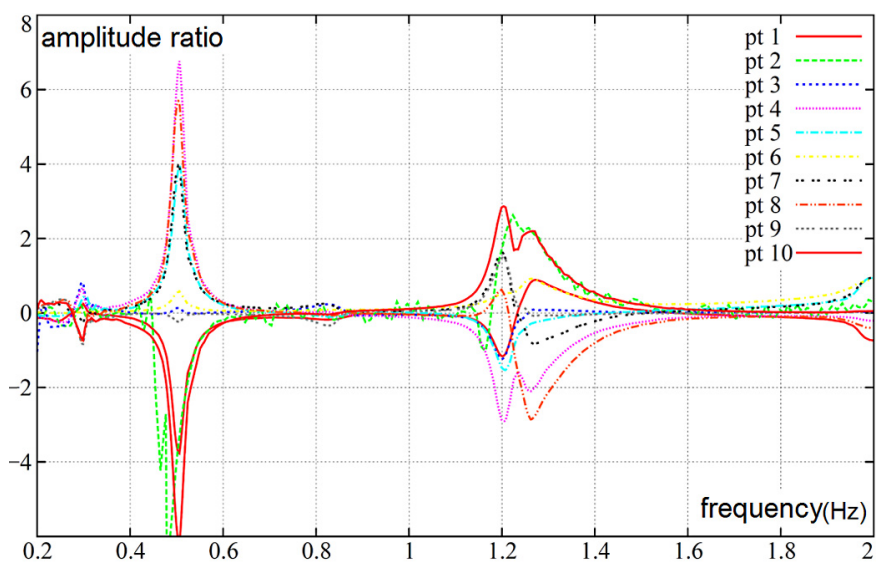

Fig. 11. Ratio of the imaginary part of displacements as a function of the excitation frequency.

flexible joints, the first frequency is affected by $22 \%$ for the frame only $(0.28 \mathrm{~Hz}$ vs. $0.36 \mathrm{~Hz})$ and $17 \%$ with cable nets $(0.72 \mathrm{~Hz}$ vs. $0.87 \mathrm{~Hz})$.

These results show that the first frequency of the scissor frame reflector is close to that of the AstroMesh for an equivalent mass. We also noted a strong influence of the cable nets on the first frequency for both of these architectures. The proposed antenna

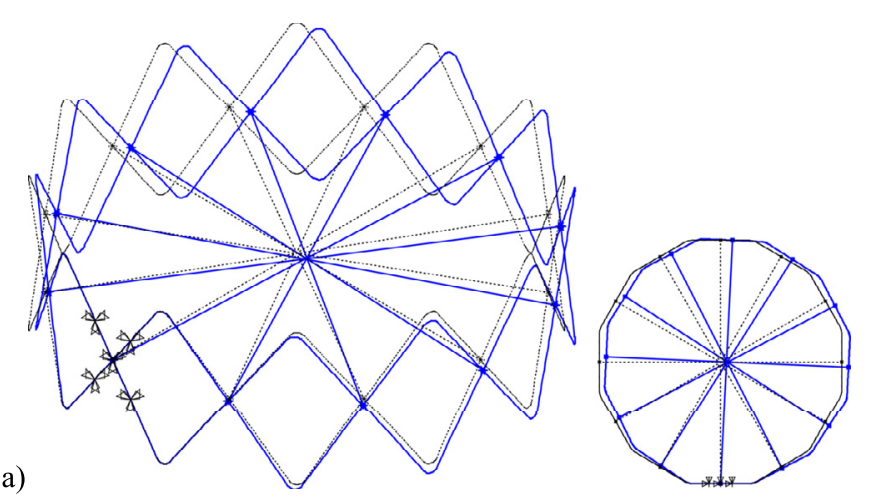

b)

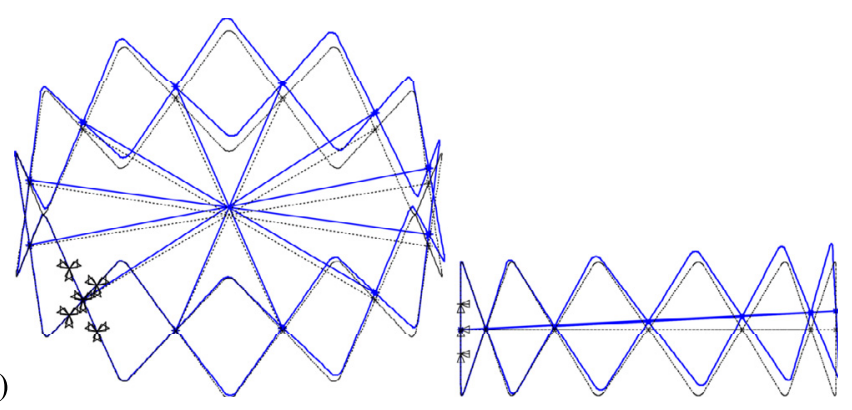

c)

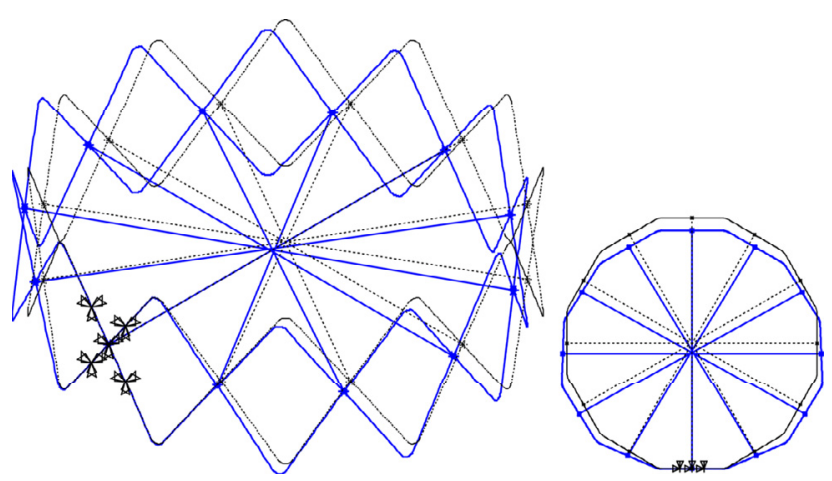

Fig. 12. Mode shapes (a) at $0.50 \mathrm{~Hz}$ (b) at $0.99 \mathrm{~Hz}$ (c) at $1.35 \mathrm{~Hz}$

concept may hence potentially meet the dynamic requirements of large space reflectors. Indeed, a higher first natural frequency can certainly be achieved by optimizing the structure. Preliminary simulations lead us to believe that a first frequency higher than $0.35 \mathrm{~Hz}$ is achievable for the rim structure with flexible joints.

\section{Ground study of scissor frame prototype}

We built a reduced scale physical model of the scissor frame architecture in order to validate the numerical model by experimental testing.

\subsection{Experimental model}

The prototype has a rim structure composed of 12 deployable scissors. It is $3.6 \mathrm{~m}$ in diameter and $1.2 \mathrm{~m}$ high in the deployed configuration. Each scissor includes two tubes connected by a pivot at mid-height. These joints consist of a calibrated steel axis $(8 \mathrm{~mm}$ diameter) that passes through the two tubes at mid-diameter into two plain bearings (Fig. 7a). The tubes are pultruded profiles in carbon fibers and epoxy resin (mass $202 \mathrm{~g}$ ). They are $1.5 \mathrm{~m}$ long with a $20 \mathrm{~mm}$ outside diameter and $1.5 \mathrm{~mm}$ thickness. The flexible joints are fitted at the tube ends. They are $1 \mathrm{~mm}$ thick and $16 \mathrm{~mm}$ wide thin blades made of carbon/epoxy composite. These blades are $20 \mathrm{~cm}$ long and pinched in $4 \mathrm{~cm}$ sleeves clamped in the split 


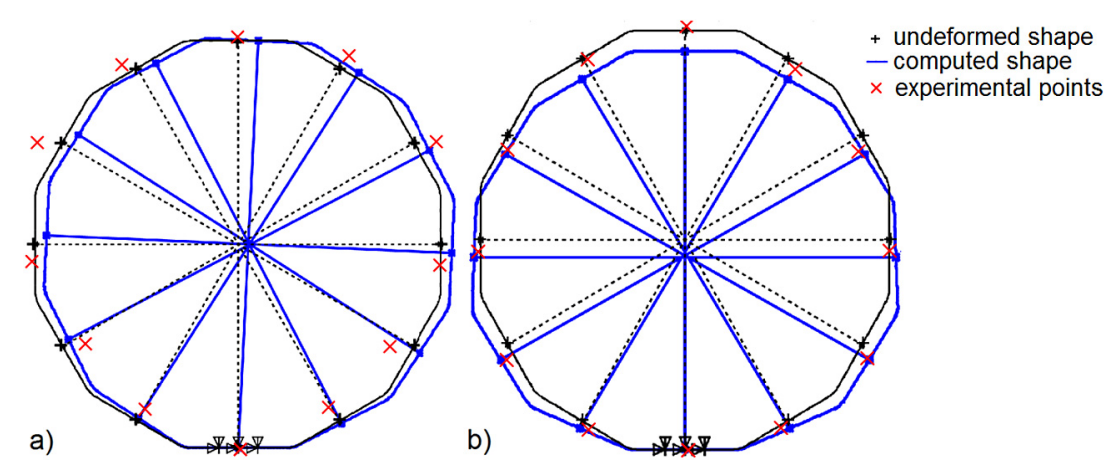

Fig. 13. Numerical and experimental mode shapes around (a) $0.5 \mathrm{~Hz}$ and (b) $1.3 \mathrm{~Hz}$.

tubes, while leaving a free length of $12 \mathrm{~cm}$ between the two ends (Fig. 7b).

The main objective of tests is to characterize the behavior of the rim structure. The cable nets were thus reduced to a minimum so as not to alter the rigidity of the whole structure. The nets are made of 6 diametric nylon threads to ensure a circular shape in the deployed configuration. The total mass of the prototype is $6.6 \mathrm{~kg}$.

To represent the attachment to the satellite, one scissor is attached to a fixed frame (Fig. 8). Moreover, the structure is suspended from the ceiling by 12 steel threads linking the scissor axes to trolleys guided by eleven rails. These rails are oriented along the theoretical trajectories of the pivots, while assuming that the structure stays circular in the deployment (Fig. 9).

\subsection{Experimental modal analysis}

To characterize the modal behavior of the deployed prototype, we performed tests using a modal exciter attached to one pivot (Fig. 10), representing the forces injected through the satellite arm. Given the low range of frequencies studied $(0.20$ to $2 \mathrm{~Hz})$, the response of the structure was measured with displacement laser sensors. The radial displacement of the excitation point and that of one pivot were then measured simultaneously (Fig. 10). The experiment was repeated for each pivot to get the displacement response, and thus model shapes, of the structure in the horizontal plane.

For each pivot, we determined the transfer function corresponding to the ratio between the signals of the two sensors. The results show resonance peaks at $0.48 \mathrm{~Hz}$ and $1.21 \mathrm{~Hz}$ (Fig. 11). There also seems to be another small peak around $0.30 \mathrm{~Hz}$ but it could not be analyzed due to the measurement resolution. In addition, two close modes seem to interact around $1.21 \mathrm{~Hz}$. As shown in Fig. 13, the measured mode shapes associated with the resonance peaks at $0.48 \mathrm{~Hz}$ and $1.21 \mathrm{~Hz}$ differ from the computed mode shapes, although eigenfrequencies are in conformity.

\section{Simulations of prototype models}

\subsection{Modal analysis in space conditions}

A modal analysis of the prototype was performed on a numerical model, derived from that used in part 2 on a $12 \mathrm{~m}$ diameter configuration. The structure is modeled in the deployed configuration and the flexible joints are considered without prestress. To represent the junction with the satellite arm, five nodes of one scissor are blocked. The 6 diametric cables are modeled by Link elements in ANSYS ${ }^{\mathrm{TM}}$, with a $0.38 \mathrm{~mm}^{2}$ section and $2 \mathrm{GPa}$ modulus of elasticity.

In a first step, the structure is described without modeling the scissor pivots in order to check that they have little influence on the eigenmodes. In this case, the first mode occurs at $0.50 \mathrm{~Hz}$ and

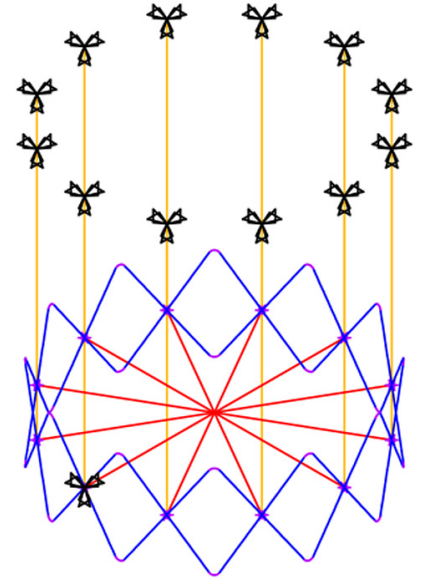

Fig. 14. Model with the suspension threads.

corresponds to an oscillation around the vertical axis of the fixed scissor (Fig. 12a). The second mode at $0.99 \mathrm{~Hz}$ is a bending oscillation in the vertical direction (Fig. 12b). The third mode at $1.35 \mathrm{~Hz}$ corresponds to an ovalization of the structure in the horizontal plane (Fig. 12c).

Although the eigenfrequencies are quite similar to those identified experimentally, the mode shapes obtained experimentally (Fig. 13) are not similar to those obtained by numerical simulation. The suspension threads seem to play a significant role by preventing the emergence among others of the second mode in bending identified numerically (Fig. 12b).

\subsection{Adaptations of the model}

To determine the reasons underlying the differences between the experimental results and the simulations, we performed several analyses by improving the modeling of the pivots and boundary conditions.

When modeling explicitly the pivots, i.e. allow a possible rotation between the tubes of each scissor, the structure naturally becomes slightly less rigid and its first mode decreases from $0.50 \mathrm{~Hz}$ to $0.44 \mathrm{~Hz}(-12 \%)$. Actually, the pivots used on the experimental prototype had substantial clearance, bringing them closer to spherical joints. When modeled as such, the first mode decreases again to $0.41 \mathrm{~Hz}(-18 \%)$. Finally, to estimate the influence of an imperfect fixation, we reduce it to one node of a pivot (zero translation and rotation at the intersection of two tubes) instead of the five nodes of the fixed scissor. The first mode frequency then switches to $0.48 \mathrm{~Hz}(-4 \%)$. In all cases, the first mode has the same shape, which suggests that the differences with the experimental results involve another parameter.

The differences between the experimental results and the simulations may also be due to the influence of the suspension threads 


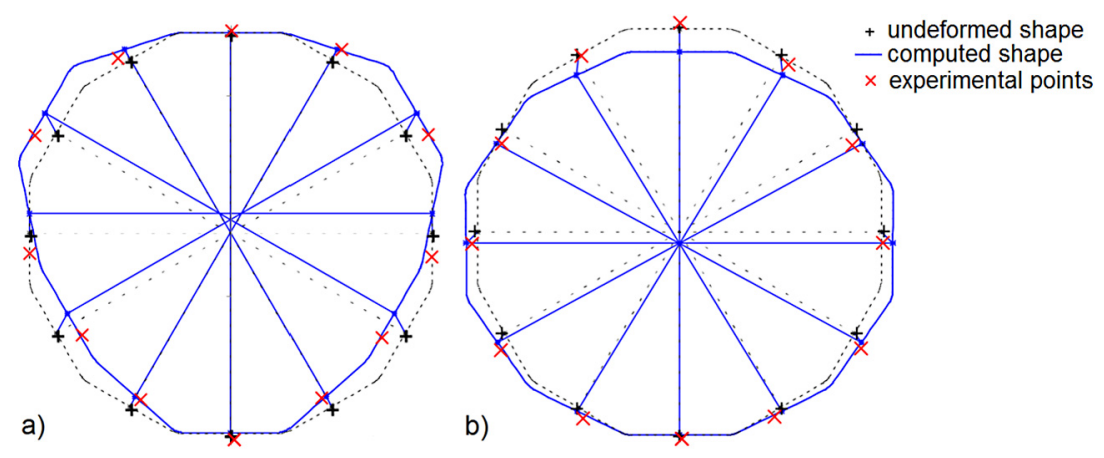

Fig. 15. Mode shapes with suspension threads (a) at $0.43 \mathrm{~Hz}$ and (b) at $1.16 \mathrm{~Hz}$.

and the incidence of an additional pendulum motion of the prototype. To check this in the simulations, we introduced the suspension threads in the model. This change only results in a disappearance of the first mode. Then we took the pendulum effect into account (Fig. 14) by attributing the pivots a moment of inertia $J=m_{s} \ell_{s}^{2} / 12$ with $m_{s}=6.6 \mathrm{~kg}$ (prototype mass) and $\ell_{s}=3.5 \mathrm{~m}$ (length of the suspension threads). This leads to a general decrease in frequency: in this case the first mode is at $0.43 \mathrm{~Hz}$ with a shape close to that of previous third mode (Fig. 12c).

The results presented in Fig. 15 were obtained by modeling the pivots, anchoring the structure by one node and including the effect of the suspension threads. The modal analysis then resulted in a first mode at $0.43 \mathrm{~Hz}$, with a shape close to the experimental mode at $0.48 \mathrm{~Hz}$. Another mode is present at $1.16 \mathrm{~Hz}$, with a shape similar to the experimental one observed at $1.21 \mathrm{~Hz}$. The shape of these two modes looks like that of the third mode of the structure in zero-gravity. Additional modes are present around these frequencies with close shapes but the measurement accuracy only suggests their existence by the peaks shape in Fig. 11 .

We note a marked influence of the suspension threads and gravity on the results of the prototype characterization tests. Indeed, the suspension threads allow keeping some of the symmetry of the zero-gravity conditions but substantially affect the first mode. The suspension threads bring a pendulum effect that does not exist in weightless environment. We also carried out numerical simulations with different stiffness of suspension threads and with anchoring points free in the plane of the ceiling but all the results of these simulations remained identical. The theoretical and experimental results matched when these effects were taken into account in the model. That allows us considering that the numerical model is able to give a good estimate of the first natural frequency of the structure in zero-gravity, which validates its use for the design of new antenna concepts.

\section{Conclusion}

In this paper, we present a new space reflector design, based on flexible joints, and analyze its dynamic behavior. Simulations of a $12 \mathrm{~m}$ diameter configuration show that this concept can meet space reflector dynamics requirements. They also reveal a substantial influence of cable nets on the first natural frequency. This could be explained by marked stiffening of the structure for a small additional mass.

An experimental prototype was built to validate the feasibility of the concept and the accuracy of numerical models using results from experimental modal analysis. However, gravity and the suspension threads significantly interfered with the prototype behavior during testing. Nevertheless, the numerical and experimental results were in conformity when taking this into account in the simulations. Thus, the proposed model can be considered suitable for simulating the modal behavior of the reflector in a weightless environment, which is of high concern for designing, in the future, new and larger scissor frame reflectors using flexible joints.

\section{Conflict of interest statement}

There is no conflict of interest.

\section{Acknowledgements}

The Laboratoire de Mécanique et Génie Civil would like to thank the Centre National d'Etudes Spatiales (CNES) for its support.

\section{References}

[1] Astro Aerospace, AstroMesh ${ }^{\mathrm{TM}}$ deployable reflector data sheet DS-409 07/04, Northrop Grumman Space Technology, 2004.

[2] C. Mangenot, et al., Large reflector antenna working group final report, ESA technical note TEC-EEA/2010.595/CM, 2010.

[3] S. Morterolle, B. Maurin, J. Quirant, C. Dupuy, Numerical form-finding of geotensoid tension truss for mesh reflector, Acta Astronaut. 76 (2012) 154-163.

[4] E. Njoku, W. Wilson, S. Yueh, et al., Spaceborne microwave instrument for high resolution remote sensing of the Earth's surface using a large-aperture mesh antenna, 2001, Jet Propulsion Laboratory Publication, document ID 20020027888, Appendix I A-17.

[5] J. Quirant, F. Cevaer, S. Morterolle, B. Maurin, J.F. Dube, Conceptual design and analysis of a deployable structure with flexible joints, J. Aerosp. Eng. 24 (2011) 277-284.

[6] M.W. Thomson, The astromesh deployable reflector, Iutam-Iass Symposium on Deployable Structures: Theory and Applications 80 (2000) 435-446.

[7] M.W. Thomson, AstroMesh deployable reflectors for Ku- and Ka-band commercial satellites, in: 20th AIAA International Communication Satellite Systems Conference and Exhibit, 2002, AIAA 2002-2032.

[8] M.W. Thomson, et al. Light-weight reflector for concentrating radiation, U.S Patent 5680145, 1997.

[9] A.G. Tibert, Deployable tensegrity structures for space applications, Doctoral thesis, Royal Institute of Technology, Dep. of Mechanics, Stockholm, Sweden, 2002.

[10] A.G. Tibert, S. Pellegrino, Deployable tensegrity reflectors for small satellites, J. Spacecr. Rockets 39 (2002) 701-709.

[11] E.L. Wilson, T. Itoh, An eigensolution strategy for large systems, Comput. Struct. 16 (1983) 259-265.

[12] Z. You, S. Pellegrino, Cable-stiffened pantographic deployable structures part 2: mesh reflector, AIAA J. 35 (8) (1997) 1348-1355 